surface of the liquid in the trough below. He also remarks that a machine could be devised which would pump up the liquid and open the stop-cocks at the proper times, and thus make the action continuous.

The paper is illustrated.

July $\mathrm{I}$.

Herbert McLeod.

\section{HATS AND HAIR.}

PUBLIC attention has been recently directed to the head-gear of civilised man, which, it is held, is neither necessary nor advantageous. We have here one of the attempts of well-meaning reformers to regulate on rational principles the dress of man, and so to assist him in his work of self-adaptation to his surroundings and needs. The object is laudable, and in all probability the scientific truth is with the reformers, but it may be well to review the question on somewhat broad lines.

The scalp is unique among the areas of the human body where hair is abundant, for there has been a notable development of hair in both sexes in this region beyond what can have existed in any of the Anthropoidea that can be placed in the human family tree. This is the more remarkable because man's pelage is a degenerating and disappearing character, except in a few areas. We must assume that when primitive man was in the making, natural selection led to the growth of thick hairy covering on his head which conduced to success in the struggle of life by protection against excessive heat and cold, against rain, and against minor injuries. As he advanced from his ancestral arboreal home into the open, and the range of his life extended, such natural adverse influences as these would call forth useful adaptive modifications, such as increased thickness and length of hair. At a later stage his developing intelligence would bring the same character under the influence of sexual or physiological selection, and this would strongly supplement the earlier factor of natural selection. Between these two factors a very stable character of the race has been produced.

There is considerable evidence that in spite of the stability of this character, the vigour of the hair on the head of man, especially in the male sex, is declining. The complexity of the conditions of civilised life renders it impossible to prove that this is due to the cessation of natural selection and the inability of sexual selection to arrest decline, but it is highly probable that this is the case. The more immediate question is this-is a decline in the growth of hair part of a general degeneration of man's ancestral pelage, or is it due to some factor introduced by man himself? It is declared by the reformers that the wearing of head-gear is responsible for the increase of premature baldness. Hitherto the discussion of the question has consisted of little more than individual opinions and ex-parte statements, and it is doubtful if evidence can prove or disprove the doctrine now being advanced. Experiment is, from the nature of the case, out of the question, because of the length of time required and the general complexity of the problem. It would seem that the nearest approach to a solution must rest on analogies derived from other characters of man himself and from the lower animals. The study of adaptive modifications (the "modifications" of Lloyd-Morgan and the "ontogenic variations" of Osborn) shows that they thrive when exposed to the natural conditions amongst which they arose, so long as these do not become excessive.

The wearing of coverings for the head affects the hair which is covered in three ways-the natural forces of sunlight, free ventilation, and movement from wind are prevented, the arteries which supply NO. I 8 IO, vOL. 7O] the skin of the scalp and nourish the hair-follicles are compressed, and nutrition thereby diminished, and the head-dress affords a culture-ground for microorganisms, being also itself impregnated with them. The absence for the time being of the germicidal effect of the sun's rays and of movement of air, and the warmth and moisture of the contained air are just those conditions which would be chosen for the culture of these low vegetable organisms. Very much of the premature baldness of men is due to dandriff (Seborrhoea sicca capillitii), a disorder of the sebaceous glands characterised by excessive secretion of sebum and its accumulation in crusts with an admixture of epithelial débris, which leads to destruction of the hair-bulbs, and this disease is essentially microbic in origin. From these various points of view it seems to be indicated that the wearing of coverings for the head slowly diminishes the vigour of the hair. If this theoretical side of the matter cannot be demonstrated, but is only extremely probable, the practical outcome of it is no less beset with difficulties. A change of custom, if desirable at all, is less called for in the case of women than of men, for in the former the head-gear is mostly of light texture and covers a very small portion of the vertex, at any rate in modern times, and a much larger surface is left exposed to sunlight and air than in the case of men. In addition to this fact it is to be remembered that the evidence for decline in the growth of hair is much less in women than in men. Those whom the practical matter chiefly concerns are children of both sexes, young adults, and all male adults, and to these the reformers speak from a sound physiological basis. Whether or not their advice will be taken, or ignored as a counsel of perfection, remains to be seen, and the change advocated is certain to be the occasion of extravagant partisanship.

Certain objections to it may be anticipated and removed. First, it will be declared to produce " colds." It is most unfortunate that this name is given to what modern medicine calls "catarrh." The belief that " colds" are produced by exposure to draughts or cold winds is dying hard, and is fortified by the old name so long applied to them, but it is to stultify the great teachings of bacteriology to invoke some casual draught as the cause of disorders of which a nasal catarrh is a type. This danger may be entirely disregarded. It would indeed be for the benefit of the public in more ways than one if they became imbued with the knowledge that pathogenic bacteria of some undetermined species are the efficient cause of all catarrhs. Secondly, it may be feared that inflammatory complaints, such as neuritis or " rheumatism " in the head, would arise from uncovering the head. This is highly improbable considering how large a surface of the head is always uncovered, and that there is no greater protection from hair in the parts uncovered than there is on the vertex. Thirdly, there is undoubtedly some danger, even in temperate climates, from exposure of the head to great sun-heat, and against this danger special precautions are and always would be taken. Fourthly, there is the danger from septic organic matter in towns. This can hardly be reckoned as important, for the area which is necessarily exposed to it is considerable, and proper hygiene of the hair would render it unimportant. Fifthly, injury to the texture of the hair from heat and cold winds is feared, and this again is negligible in view of the fact that the already uncovered parts of the head are better provided with vigorous hair than the covered parts.

Whether the reformers have scientific truth on their side or not, it is possible that the zsthetic aspect of the matter will prove the stronger. 